\title{
EFFECTIVENESS OF C1-C2 SUSTAINED NATURAL APOPHYSEAL GLIDE COMBINED WITH DRY NEEDLING ON PRESSURE POINT THRESHOLD AND HEADACHE DISABILITY IN CERVICOGENIC HEADACHE
}

\author{
RAMESH CHANDRA PATRA ${ }^{1 *}$, PATITAPABAN MOHANTY ${ }^{2}$, AJAY P GAUTAM ${ }^{1}$ \\ ${ }^{1}$ Department of Physiotherapy, Lovely Professional University, Phagwara, Punjab, India. ${ }^{2}$ Department of Physiotherapy, Swami Vivekanand \\ National Institute of Rehabilitation Training and Research, Odisha, India. Email rameshbmc22@gmail.com
}

Received: 02 September 2017, Revised and Accepted: 07 October 2017

ABSTRACT

Objective: The main objective of this study was to evaluate the effectiveness of dry needling and mulligan C1-C2 sustained natural apophyseal glides (SNAGs) in increasing pressure point threshold and reducing headache disability in patients with CGH.

Methods: This study was conducted on 150 patients. They were divided into three groups for the purpose of the study. Group A was referred to as the dry needling group. They were subjected to dry needling for treating the pain. Group B was the manual therapy group. The patients in this group were subjected to C1-C2 SNAGs. Group C was the combined group. Patients belonging to this group were given C1-C2 SNAGs along with dry needling.

Results: Statistical analysis paired t-test was used for comparison of the mean within every group where it showed significant improvement in all the parameter $(\mathrm{p}<0.05)$.

Conclusion: There was a consistent reduction in tenderness and improvement in disability of the patients belonging to all groups. However, Group C, where the patients were subjected to combined treatment, showed better results. Results of this study indicate that dry needling along with mulligan C1-C2 SNAGs is more beneficial in patients suffering from cervicogenic headaches.

Keywords: Cervicogenic headaches, Dry needling, C1-C2 sustained natural apophyseal glides, Pressure point threshold, Headache disability.

(C) 2018 The Authors. Published by Innovare Academic Sciences Pvt Ltd. This is an open access article under the CC BY license (http://creativecommons. org/licenses/by/4. 0/) DOI: http://dx.doi.org/10.22159/ajpcr.2018.v11i1.22349

\section{INTRODUCTION}

Cervicogenic headache (CGH) was first described by Dr. Sjaastad et al. in 1983 [1]. The pain arises from the upper cervical spine and is referred to one side of the head and/or face. Neck movement, awkward head position for a long time or any external pressure over the upper cervical or occipital regions on the side of pain worsens the condition and intensifies the pain (Chaibi and Russell, 2012). The International Headache Society (IHS) has declared CGH as a secondary type of headache [2]. The main cause of CGH is dysfunction in the upper cervical spine, and the mechanism of headache involves nociceptive structures such as the disks, upper cervical spinal nerves, facet joints, ganglia, muscles, and ligaments [3]. The prevalence of CGH in global population is $2.5-4.1 \%$ out of which females are more prone to this disease as the male to female ratio is $1: 4[4,5]$. CGH represents a major health problem with tenderness and low quality of life [8]. Many studies have proved that patients with CGH represent a sever trigger point and low pressure point threshold (PPT) in cervical muscles [6,7].

Several invasive and non-invasive methods exist for treating the CGH $[19,20,22,26]$. In spite of being a musculoskeletal disorder, very little focus is given on the muscle system. Dry needling has grown in popularity and it is a relatively unique part of physical therapy practice. Number of studies has suggested that dry needling is a very effective technique to manage the musculoskeletal disorder [5-7]. Several studies also support that mulligan's C1-C2 sustained natural apophyseal glides (SNAGs) are a useful technique to reduce pain and improving range of motion [10-12]. Many studies suggested that multimodal treatment is more beneficial in neck disorder $[8,9,20,21]$. The main purpose of this study was to investigate the combined effects of C1-C2 SNAGs and dry needling in a patient with CGH in improving PPT and reducing headache disability.

\section{METHODS}

The study was a randomized clinical trial. All the necessary ethical clearances were obtained before starting the trial. All the subjects were evaluated at Lovely Professional University, Phagwara, Punjab. The study was conducted from February 2014 to December 2016. Criteria for inclusion were that the candidate can be of either gender; should be in the age category of 20-50 years and should fulfill the guidelines set by IHS (Bond and Kinslow, 2015). Exclusion criteria were: Cervical spine injury or surgery, congenital spinal deformity, participants younger than 20 or older than 50 years, cervical radiculopathy, the participants had experienced any recent trauma if suffering from dizzy spells, vertebral malignancy, vertebral-basilar insufficiency, bone infections, and fracture. Furthermore, participants who were taking anti-inflammatory or muscle relaxant medication and participants who did not sign the consent form were excluded. A written consent was taken from all the patients before being subjected to any form of therapy. Then, they were divided into three categories: Group A, Group B, and Group C through lottery method.

Group A was given dry needling therapy; Group B was given manual therapy and patients in Group C were given a combination of both manual therapy and dry needling. Patients of all the groups were advised to take all the active range of motion exercises.

Outcome measurements were taken at the baseline. Further, these measurements were taken after a 6 week intervention period. Algometer [25] was used to measure the PPT while SP-36 questionnaire $[23,24]$ was used for measuring the quality of life.

\section{Manual therapy}

The patients in the manual therapy group were given mulligan proposed C1-C2 SNAGS [26]. While providing manual therapy, the 
patient was in a sitting position and therapist was standing at his or her side. The therapist then asked the patient to move his or her head in the painful direction. The patient's head was stabilized by the forearm and the body of the therapist. The therapist then placed first three fingers around the base of the skull to hold it, and the little finger lay over the spinous process of $\mathrm{C} 2$ vertebra. Then, the lateral border of the thenar eminence of other hand was laid over the little finger of the first hand. Pressure was applied to the spinous process of C2 toward eyeball, and the skull remained stable while giving glide. The glide was maintained 3 times per second, and the procedure was repeated 6-10 times [27].

\section{Dry needling technique}

A $15 \mathrm{~mm}$ acupuncture needle was used for suboccipital muscle and $40 \mathrm{~mm}$ needle was used for paraspinal and trapezius muscle. All the necessary precautions were maintained before inserting the needle. Therapists wore hand gloves for all purposes. First, the treatment area was cleaned using an antiseptic liquid. This was followed by the identification of the trigger point through palpitation. The client was informed beforehand about the oncoming pinprick sensations, and then the needle was inserted into the muscle.

\section{Statistical analysis}

Data were analyses using SPSS, version 16.0. Paired t-test was used for comparison of pre- and post-values within the group. One-way ANOVA and Scheffe post hoc tests were used for between the group comparisons. Level of significance for this study was fixed at $5 \%(\mathrm{p}<0.05)$.

\section{Protocol for the present study}

Fig. 1 shows a flowchart depicting all the different steps of this study.

\section{RESULTS}

A total of 150 subjects were analyzed. Table 1 summarizes the demographic information of all the patients' indifferent groups. Furthermore, the comparison of PPT between Group A and Group C showed notable improvement (Table 2). Comparison of headache disability between the groups showed a significant difference in the patients of Group C (Table 3). Results have shown that there was a significant change the condition of all the patients after the therapy as clearly shown in Table 3.

\section{DISCUSSION}

Evidence suggests that CGH is a multidimensional musculoskeletal disorder. Evidence suggests that nowadays the application of physiotherapy treatment has been changed [28]. The main aim of this study was to evaluate the additional benefits of dry needling along with manual therapy in patients suffering from CGH. The results have showed that there was a statistically significant improvement in all the groups in term of disability and PPT. However, post-intervention analysis showed that there were noteworthy improvements in disability, in Group C. Furthermore, PPT improvement was observed in both the Groups A and C, but not in the Group B. The PPT was found over the base of skull, paraspinal muscle (C5-C6 level), and in the trapezius muscle in all the groups.

The changes found in this study were as follows. Group A $0.5 \mathrm{~kg} / \mathrm{cm}^{2}$ in suboccipital region $0.52 \mathrm{~kg} / \mathrm{cm}^{2}$ in C5-C6 region, $1.09 \mathrm{~kg} / \mathrm{cm}^{2}$ over trapezius. In Group B $0.51 \mathrm{~kg} / \mathrm{cm}^{2}$ in suboccipital region $0.04 \mathrm{~kg} / \mathrm{cm}^{2}$ in C5-C6 region, $0.1 \mathrm{~kg} / \mathrm{cm}^{2}$ over trapezius. $0.69 \mathrm{~kg} / \mathrm{cm}^{2}$ in suboccipital region $0.63 \mathrm{~kg} / \mathrm{cm}^{2}$ in $\mathrm{C} 5-\mathrm{C} 6$ region, $1.55 \mathrm{~kg} / \mathrm{cm}^{2}$ over trapezius.

This indicate that dry needling and dry needling combined with manual therapy have shown significant improvement in the condition of the patient. Pressure point was measured as the most painful trigger point area which was found out to be the suboccipital area, C5-C6 paraspinal

Table 1: Demographic data of all the patients

\begin{tabular}{lllll}
\hline Group & $\boldsymbol{N}$ & Age & M & W \\
\hline Group A & 39 & $38 \pm 9$ & 11 & 28 \\
Group B & 38 & $37 \pm 9$ & 13 & 25 \\
Group C & 37 & $36 \pm 8$ & 13 & 24 \\
Total & 114 & $37 \pm 8$ & 37 & 77 \\
\hline
\end{tabular}

The values are depicted as mean value \pm SD; $N$ : Number of patient, M: Men, W: Women. SD: Standard deviation

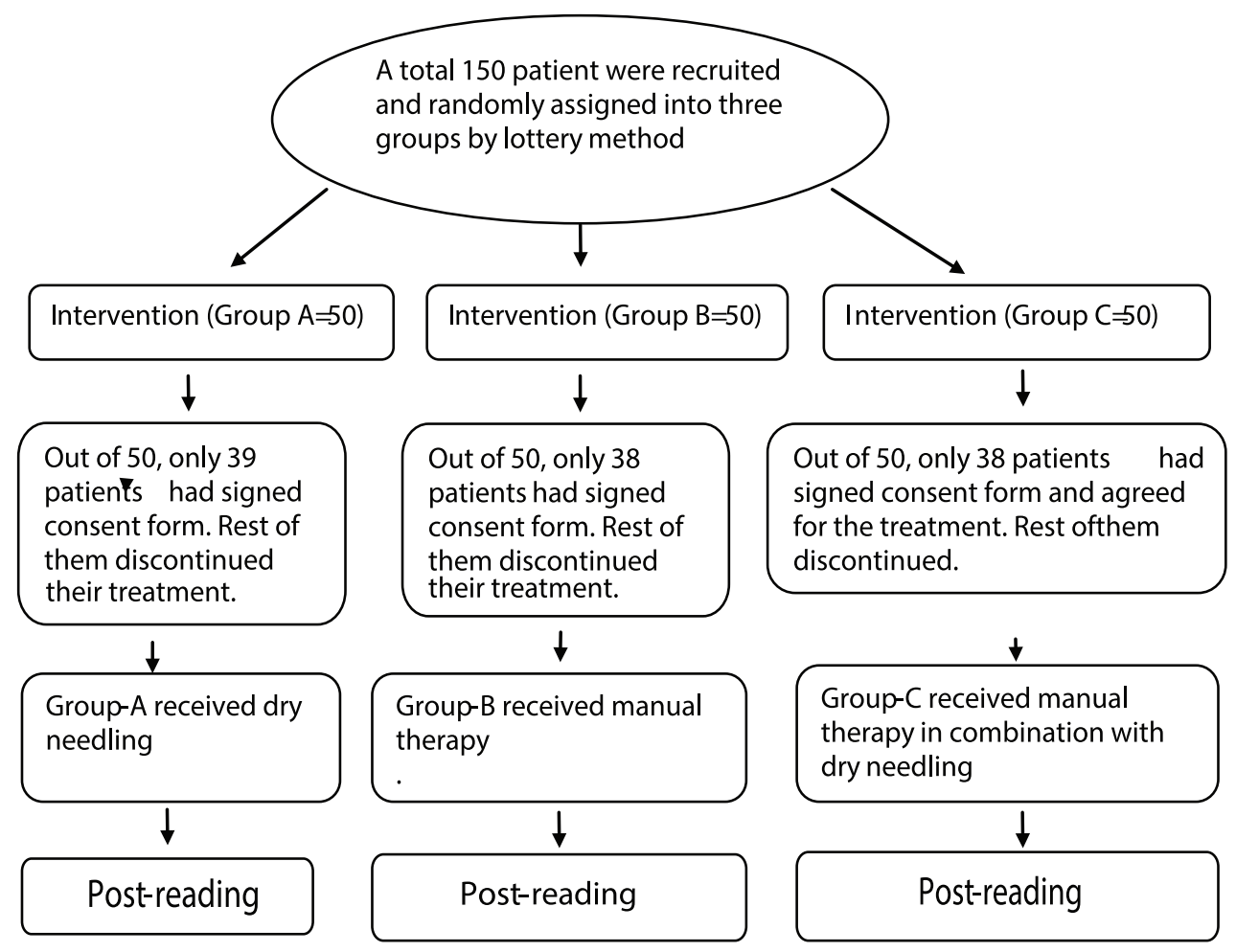

Fig. 1: A flowchart depicting all the different steps of this study 
Table 2: Post hoc test for PPT and HDI

\begin{tabular}{llll}
\hline Comparison between the group & PPT-1 (p value) & PPT-2 (p value) & PPT-3 (p value) \\
\hline Group A and Group B & 0.001 & 0.001 & 0.001 \\
Group B and Group C & 0.001 & 0.001 & 0.988 \\
Group A and Group C & 0.998 & 0.935 & 0.001 \\
\hline
\end{tabular}

PPT: Pressure point threshold, HDI: Headache disability index

Table 3: Paired test for PPT and HDI

\begin{tabular}{|c|c|c|c|c|c|}
\hline \multirow[t]{2}{*}{ Group } & \multirow[t]{2}{*}{ Outcome } & \multicolumn{2}{|l|}{ Mean $\pm S D$} & \multirow[t]{2}{*}{ Differences within the group } & \multirow[t]{2}{*}{$p$ value } \\
\hline & & Pre & Post & & \\
\hline \multirow[t]{4}{*}{ Group A } & HDI & $58.87 \pm 10.46$ & $22.15 \pm 6.38$ & 36.72 & 0.0001 \\
\hline & PPT-1 & $2.73 \pm 0.6$ & $3.23 \pm 0.63$ & 0.5 & 0.0001 \\
\hline & PPT-2 & $2.24 \pm 0.64$ & $2.76 \pm 0.7$ & 0.52 & 0.0001 \\
\hline & PPT-3 & $3.43 \pm 0.63$ & $4.52 \pm 0.87$ & 1.09 & 0.0001 \\
\hline \multirow{4}{*}{ Group B } & HDI & $58.59 \pm 9.23$ & $22.64 \pm 6.20$ & 35.95 & 0.0001 \\
\hline & PPT-1 & $2.57 \pm 0.61$ & $3.08 \pm 0.67$ & 0.510 & 0.0001 \\
\hline & PPT-2 & $2.34 \pm 0.53$ & $2.38 \pm 0.54$ & 0.04 & 0.1340 \\
\hline & PPT-3 & $3.38 \pm 0.63$ & $3.48 \pm 0.87$ & 0.100 & 0.1700 \\
\hline \multirow[t]{4}{*}{ Group C } & HDI & $57.58 \pm 9.99$ & $10.28 \pm 7.21$ & 47.3 & 0.0001 \\
\hline & PPT-1 & $2.57 \pm 0.69$ & $3.26 \pm 0.68$ & 0.69 & 0.0001 \\
\hline & PPT-2 & $2.34 \pm 0.56$ & $2.97 \pm 0.57$ & 0.63 & 0.0001 \\
\hline & PPT-3 & $3.39 \pm 0.64$ & $4.94 \pm 1.44$ & 1.55 & 0.0001 \\
\hline
\end{tabular}

HDI: Headache disability index, PPT-1: Pressure point threshold over suboccipital area, PPT-2: Pressure point threshold over C5-C6 paraspinal area, PPT-3: Pressure point threshold over the trapezius muscle, SD: Standard deviation

area, and over trapezius muscle. All most all the three points depicted substantial improvement. This result obtained could be because of intramuscular mechanical pressure resulting from the insertion of needle. The mechanism behind this could be due to increased blood flow and stimulation of the nociceptive substances, as evident, by a number of experiments conducted by researchers all over the world [9-12].

It may also stimulate $\mathrm{A} \delta$ fibers and activate inhibitory pain gate mechanism [13]. In addition, reactive hyperemia might occur after needle insertion and may reduce muscle spasm due to spinal reflex mechanism [14]. This result agree with another study which was conducted by Ziaeifar et al., who observed that dry needling produces significant improvement in PPT for subjects with myofascial trigger point in upper trapezius muscles [16]. Another study conducted by Llamas-Ramos et al. suggested that trigger point dry needling and trigger point manual therapy are similarly effective on PPT in a patient with chronic mechanical neck pain [15]. A randomized clinical trial also reported increased PPT after dry needling in patients with acute mechanical neck pain [17].

The significant improvement of headache disability shown in combined group in post-intervention analysis has not been observed in the other two groups. Post-intervention measurement exhibited 36-point changes in Group-A and 35-point changes in Group B. However, the maximum changes were seen in Group C, i.e., 47 points. There is a lack of evidence for reduction of headache disability in physical therapy intervention. A study conducted by Bond et al. in 2015 showed 28-point changes after four sessions of dry needling (over 2 weeks) in patients having occipital neuralgia [18]. The outcome of this study agrees with our observations.

\section{Limitations of the study}

Limitations included the short duration of therapy. The age criteria, which were set at 20-50 years, served as another limitation.

\section{CONCLUSION}

The present study has shown that all three treatment groups (Group A, Group B, and Group C) have experienced beneficial effects after being subjected to treatment for CGH. However, Group $\mathrm{C}$ showed significantly more improvement in increasing PPT and decreasing the HDI in patients. Hence, the combined intervention of manual therapy and dry needling is recommended as a more effective and suitable method for treating CGH among patients.

\section{AUTHORS CONTRIBUTION--}

Ramesh Chandra Patra-Project work and reports writing PATITAPABAN MOHANTY-Review of the article AJAY P GAUTAM-Data analysis and review the article

\section{CONFLICTS OF INTERESTS}

The author does not have any conflicts of interests

\section{REFERENCES}

1. Sjaastad O, Saunte C, Hovdahl H, Breivik H, Grønbaek E. "Cervicogenic" headache. An hypothesis. Cephalalgia 1983;3:249-56.

2. Headache Classification Committee of the International Headache Society (IHS). The international classification of headache disorders, $3^{\text {rd }}$ edition (beta version). Cephalalgia 2013;33:629-808.

3. Pöllmann W, Keidel M, Pfaffenrath V. Headache and the cervical spine: A critical review. Cephalalgia 1997;17:801-16.

4. Haldeman S, Dagenais S. Cervicogenic headaches: A critical review. Spine J 2001;1:31-46.

5. Sjaastad O, Bakketeig LS. Prevalence of cervicogenic headache: Vågå study of headache epidemiology. Acta Neurol Scand 2008;117:173-80.

6. Hall T, Briffa K, Hopper D. Clinical evaluation of cervicogenic headache: A clinical perspective. J Man Manip Ther 2008;16:73-80.

7. Bovim G. Cervicogenic headache, migraine, and tension-type headache. Pressure-pain threshold measurements. Pain 1992;51:169-73.

8. Diener I. The impact of cervicogenic headache on patients attending a private physiotherapy practice in Cape Town. S Afr J Physiother 2001;57:35-9.

9. Cagnie B, Dewitte V, Barbe T, Timmermans F, Delrue N, Meeus M. Physiologic effects of dry needling. Curr Pain Headache Rep 2013;17:348.

10. Pecos-Martín D, Montañez-Aguilera FJ, Gallego-Izquierdo T, Urraca-Gesto A, Gómez-Conesa A, Romero-Franco $\mathrm{N}$, et al. Effectiveness of dry needling on the lower trapezius in patients with mechanical neck pain: A randomized controlled trial. Arch Phys Med Rehabil 2015;96:775-81.

11. Cagnie B, Barbe T, De Ridder E, Van Oosterwijck J, Cools A, Danneels L. The influence of dry needling of the trapezius muscle on muscle blood flow and oxygenation. J Manipulative Physiol Ther 
2012;35:685-91.

12. Shah JP, Phillips TM, Danoff JV, Gerber LH. An in vivo microanalytical technique for measuring the local biochemical milieu of human skeletal muscle. J Appl Physiol 2005;99:1977-84.

13. Baldry PE. Acupuncture, Trigger Points and Musculoskeletal Pain. Edinburgh: Elsevier, Churchill Livingstone; 2005.

14. Hou CR, Tsai LC, Cheng KF, Chung KC, Hong CZ. Immediate effects of various physical therapeutic modalities on cervical myofascial pain and trigger-point sensitivity. Arch Phys Med Rehabil 2002;83:1406-14.

15. Llamas-Ramos R, Pecos-Martín D, Gallego-Izquierdo T, Llamas-Ramos I, Plaza-Manzano G, Ortega-Santiago R, et al. Comparison of the short-term outcomes between trigger point dry needling and trigger point manual therapy for the management of chronic mechanical neck pain: A randomized clinical trial. J Orthop Sports Phys Ther 2014;44:852-61.

16. Ziaeifar M, Arab AM, Karimi N, Nourbakhsh MR. The effect of dry needling on pain, pressure pain threshold and disability in patients with a myofascial trigger point in the upper trapezius muscle. J Bodyw Mov Ther 2014;18:298-305.

17. Mejuto-Vázquez MJ, Salom-Moreno J, Ortega-Santiago R, Truyols-Domínguez S, Fernández-de-Las-Peñas C. Short-term changes in neck pain, widespread pressure pain sensitivity, and cervical range of motion after the application of trigger point dry needling in patients with acute mechanical neck pain: A randomized clinical trial. J Orthop Sports Phys Ther 2014;44:252-60.

18. Bond BM, Kinslow C. Improvement in clinical outcomes after dry needling in a patient with occipital neuralgia. J Can Chiropr Assoc
2015;59:101-10

19. Chaibi A, Russell MB. Manual therapies for cervicogenic headache: A systematic review. J Headache Pain 2012;13:351-9.

20. Sillevis $\mathrm{R}$. The use of dry needling in combination with manual therapy techniques for a patient with cervicogenic headache: A case report. J Phys Ther 2011;3:9-18.

21. France S, Bown J, Nowosilskyj M, Mott M, Rand S, Walters J. Evidence for the use of dry needling and physiotherapy in the management of cervicogenic or tension-type headache: A systematic review. Cephalalgia 2014;34:994-1003.

22. Kassem AA, Labib GS. Flash dissolving sublingual almotriptan malate lyotabs for management of migraine. Int $\mathrm{J}$ Pharm Pharm Sci 2017;9:125-31.

23. Ware JE, Sherbourne CD. The MOS 36-ltem short-form health survey (SF-36). Med Care 1992;30:473-83.

24. Ware JE Jr, Gandek B. Overview of the SF-36 health survey and the international quality of life assessment (IQOLA) project. J Clin Epidemiol 1998;51:903-12.

25. Kinser AM, Sands WA, Stone MH. Reliability and validity of a pressure algometer. J Strength Cond Res 2009;23:312-4.

26. Hall T, Chan HT, Christensen L, Odenthal B, Wells C, Robinson K. Efficacy of a C1-C2 self-sustained natural apophyseal glide (SNAG) in the management of cervicogenic headache. J Orthop Sports Phys Ther 2007;37:100-7.

27. Wade PG, Franklin VJ. The effect of mobilisation and core muscle strengthening for cervical spine in relieving cervicogenic headache. IOSR J Nursing Health Sci 2015;4:1316. 